\title{
Adsorption of Neutral Red from Aqueous Solution by Wheat Husk in a Fixed-bed Column
}

\author{
Yubin Jiao ${ }^{a}$, Jaiqi Zhang ${ }^{b}$, Gening $\mathrm{Bi}^{\mathrm{c}}$, Runping Han ${ }^{\mathrm{d}_{*}}$ \\ School of Chemistry and Molecular Engineering, Zhengzhou University, Kexue Road 100, \\ Zhengzhou, 450001, PR China \\ aemail: 361116201@qq.com, bemail: bs1517@163.com, cemail: 634487467@qq.com, \\ d* Corresponding author email: rphan67@zzu.edu.cn
}

\begin{abstract}
Keywords: Wheat husk; Column adsorption; Neutral Red; Thomas model
Abstract. In this study, the ability of wheat straw to adsorb neutral red (NR) from aqueous solution was investigated in a fixed-bed column. The effects of the flow rate, the influent concentration of NR and bed depth on breakthrough curves, were studied. The adsorption quantity was $26.4 \mathrm{mg} / \mathrm{g}$ at initial NR concentration of $50 \mathrm{mg} / \mathrm{L}$, flow rate of $10.0 \mathrm{~mL} / \mathrm{min}$ and bed depth of $8.0 \mathrm{~cm}$. The Thomas model was applied to fit the experimental data and the results showed that it was available to predict the breakthrough curves and to determine the characteristic parameters of the column useful for process design using nonlinear regression.
\end{abstract}

\section{Introduction}

Color is a visible pollutant and the presence of even a very minute amount of coloring substance makes it undesirable due to its appearance. Adsorption techniques are proved to be an effective and attractive process for removal of refractory pollutants (including dyes) from wastewater [1]. The widely used and effective physical method in industry is activated carbon, but the high cost limited its widespread use. There is thus a growing need to use a low cost, renewable, and easily available adsorbent material. So attentions have been focused on the development of low cost adsorbent for the application of wastewater treatment [2]. There were several reviews about this field [3-6].

Agricultural by-product, wheat straw (WS) was obtained extensively and cheaply as a byproduct obtained from agriculture in China. It contains abundant floristic fiber, protein and some functional groups such as carboxyl, hydroxyl, etc, which make adsorption processes possible. As a matter of fact, WS or modified WS can be selected as an adsorbent to remove dyes and heavy metal ions from solution [7-12].

One of the cationic dyes, Neutral Red (NR), is selected as the adsorbate. The aim of this study is to develop a cheap technology for the removal of NR from solution in column mode. The objectives of present work were to investigate effects of flow rate, influent concentration and bed depth on NR adsorption by WS bed column. Thomas model was used to predict the performance.

\section{Materials and methods}

Materials. The wheat straw (WS) used in the present investigation was obtained from the local countryside. The collected materials were washed with distilled water several times to remove all the dirt particles. The washed material was dried in an oven at $373 \mathrm{~K}$ for a period of $24 \mathrm{~h}$ and then ground and screened through a set of sieves to get the geometrical sizes (20 to 40) mesh for column studies. NR (C.I.50040, FW=288.8) was purchased from Zhengzhou Chemical Company, China. The stock solutions of NR (500 mg/L) were prepared in distilled water. Working solution of NR was diluted to desired concentration with distilled water and $\mathrm{pH}$ of $\mathrm{NR}$ solution is 6.5 and it is not adjusted.

Methods. Fixed-bed column adsorption experiments were carried out using WS packed into a glass column $(1.0 \mathrm{~cm}$ inner diameter and $25 \mathrm{~cm}$ in height). A series of experiments were conducted with various influent NR solution with columns. The experiments were conducted in down flow mode through the fixed-bed with a peristaltic pump. The temperatures of all experiments were $293 \mathrm{~K}$.

WS was packed into a glass column. The Except the bed depth, the mass of adsorbent in the 
column was $1.0 \mathrm{~g}(8 \mathrm{~cm})$. The NR solution of known concentration was pumped to the column $(8.0$ $\mathrm{cm}$ ) in a down-flow direction by a peristaltic pump at 7, 10 or $13 \mathrm{~mL} / \mathrm{min}$, respectively. Also, the experiments of three different bed depths, $5 \mathrm{~cm}, 8 \mathrm{~cm}, 11 \mathrm{~cm}$, were operated at the same influent NR concentration (50 $\mathrm{mg} / \mathrm{L})$ and flow rate $(8 \mathrm{~mL} / \mathrm{min})$, respectively.

Samples were collected at regular intervals in all the adsorption. The concentration of NR in effluent was analyzed using a UV/Vis-3000 spectrophotometer (Shimadzu, Japan) by monitoring the absorbance changes at a wavelength of maximum absorbance $(530 \mathrm{~nm})$. The loading behavior of NR in a fixed-bed column is usually expressed in term of $C_{t} / C_{0}\left(C_{0}\right.$ is the influent NR concentration, $C_{\mathrm{t}}$ is the effluent concentration at any time $t, \mathrm{mg} / \mathrm{L}$ ) as a function of time or volume of the eluate and then the breakthrough curves can be obtained according to $C_{t} / C_{0}$ to time $t$.

\section{Results and discussions}

Effect of influent NR concentration on breakthrough curves. The breakthrough curves at different NR concentration were shown in Fig. 1. It was illustrated that the breakthrough time decreased with increasing influent NR concentration. At lower influent concentrations, breakthrough occurred slower. As influent concentration increased, sharper breakthrough curves were obtained. These results demonstrate that the change of concentration gradient affects the saturation rate and breakthrough time.

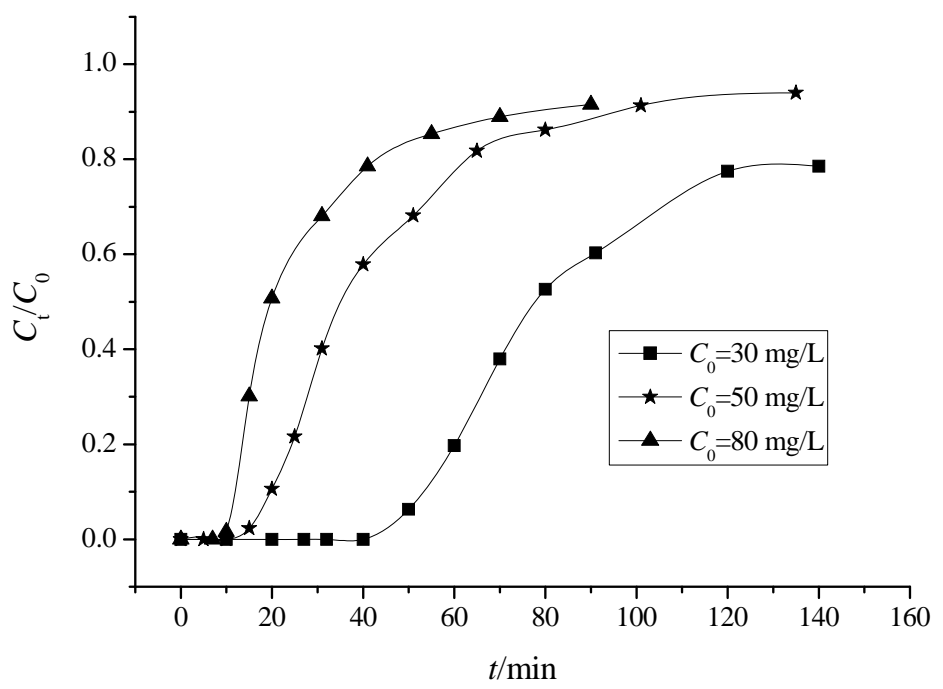

Fig. 1. Effect of NR concentration on breakthrough curves $(v=10 \mathrm{~mL} / \mathrm{min}, \mathrm{Z}=8 \mathrm{~cm})$.

Effect of flow rate on breakthrough curves. The breakthrough curves at various flow rates were shown in Fig. 2. It was shown that breakthrough generally occurred faster with higher flow rate. Breakthrough time reaching saturation was increased significantly with a decreased in the flow rate. When at a low rate of influent, NR had more time to contact with WS and it resulted in higher removal of NR ions from solution in column. 


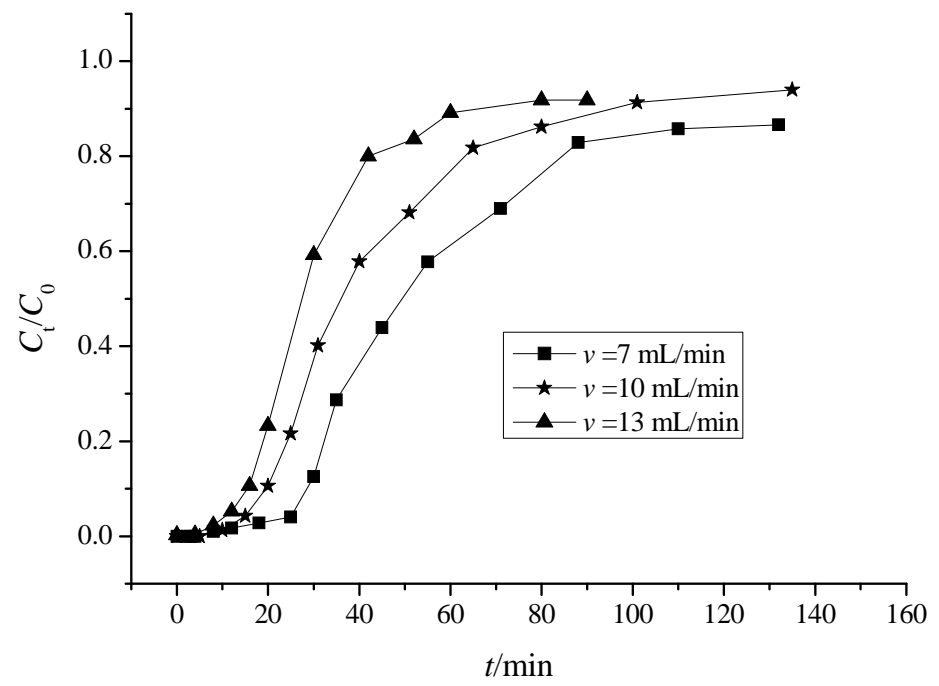

Fig. 2. Effect of flow rate on breakthrough curves $\left(C_{0}=50 \mathrm{mg} / \mathrm{L}, \mathrm{Z}=8 \mathrm{~cm}\right)$.

Effect of bed height on breakthrough curves. The breakthrough curves at different bed depth were shown in Fig. 3. From Fig. 3, as the bed height increases, NR had more time to contact with WS that resulted in higher removal efficiency of NR ions in column. So the higher bed column results in a decrease in the solute concentration in the effluent at the same time. The slope of breakthrough curve decreased with increasing bed height, which resulted in a broadened mass transfer zone [13].

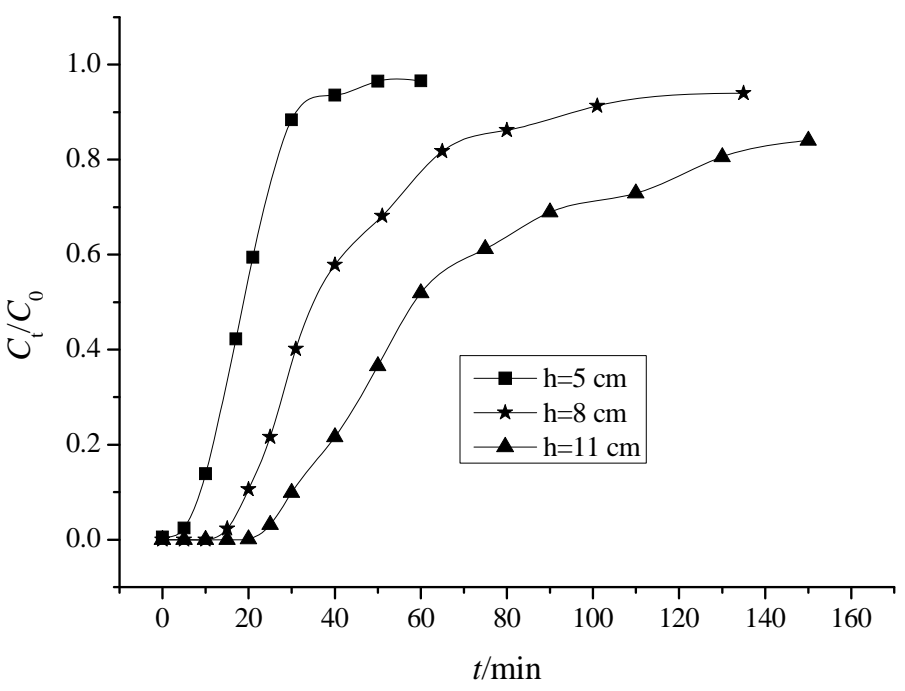

Fig. 3. Effect of bed depth on breakthrough curves $\left(C_{0}=50 \mathrm{mg} / \mathrm{L}, v=10 \mathrm{~mL} / \mathrm{min}\right)$.

The maximum column capacity, $q_{\text {total }}(\mathrm{mg})$, for a given feed concentration and flow rate is equal to the area under the plot of the adsorbed NR concentration $C_{\mathrm{ad}}\left(C_{\mathrm{ad}}=C_{0}-C\right)(\mathrm{mg} / \mathrm{L})$ versus time (min) and is calculated from $\mathrm{Eq}(1)$ [13]:

$$
q_{\text {total }}=\frac{v A}{1000}=\frac{v}{1000} \int_{t=0}^{t=t_{\text {toal }}} C_{a d} d t
$$

where $t_{\text {total }}, v$ and $A$ are the total flow time $(\mathrm{min})$, volumetric flow rate $(\mathrm{mL} / \mathrm{min})$ and the area under the breakthrough curve, respectively.

The equilibrium uptake $\left(q_{\mathrm{e}}\right)$, the weight of NR adsorbed per unit dry weight of adsorbent(mg/g) in the column, is calculated as following: 


$$
q_{\mathrm{e}}=\frac{q_{\text {total }}}{x}
$$

where $x$ is the total dry weight of WS in column (g).

The values of qe at various conditions were listed in table 1. From table 1, the adsorption quantity is over $20 \mathrm{mg} / \mathrm{g}$ and operated conditions can affect the quantity.

Application of Thomas models. Thomas model is one of the most general and widely used models in column performance theory. The expression by Thomas for an adsorption column is given as follows [13-15]:

$$
\frac{C_{\mathrm{t}}}{C_{0}}=\frac{1}{1+\exp \left(k_{\mathrm{Th}} q_{0} x / v-k_{\mathrm{Th}} C_{0} t\right)}
$$

where $k_{\mathrm{Th}}$ is the Thomas rate constant (mL/min mg); $q_{0}$ is the equilibrium NR uptake per $g$ of the adsorbent (mg/g); $x$ is amount of adsorbent in the column $(\mathrm{g}) ; v$ is flow rate $(\mathrm{mL} / \mathrm{min})$.

Table 1 also listed the parameters of Thomas model and determined coefficients by nonlinear regression analysis using least square method.

Table 1 Parameters of Thomas model by nonlinear regressive analysis

\begin{tabular}{ccccccc}
\hline $\begin{array}{c}C_{0} / \\
(\mathrm{mg} / \mathrm{L})\end{array}$ & $\begin{array}{c}v / \\
(\mathrm{mL} / \mathrm{min})\end{array}$ & $\begin{array}{c}\mathrm{Z} / \\
(\mathrm{cm})\end{array}$ & $\begin{array}{c}k_{\mathrm{Th}} / \\
(\mathrm{mL} / \mathrm{mg} \min )\end{array}$ & $\begin{array}{c}q_{0} / \\
(\mathrm{mg} / \mathrm{g})\end{array}$ & $\begin{array}{c}q_{\mathrm{e}} / \\
(\mathrm{mg} / \mathrm{g})\end{array}$ & $R^{2}$ \\
\hline 50.0 & 7.0 & 8.0 & 1.50 & 25.3 & 25.2 & 0.965 \\
50.0 & 10.0 & 8.0 & 1.70 & 24.9 & 26.4 & 0.963 \\
50.0 & 13.0 & 8.0 & 2.56 & 24.3 & 27.6 & 0.967 \\
30.0 & 10.0 & 8.0 & 1.47 & 34.0 & 33.5 & 0.919 \\
80.0 & 10.0 & 8.0 & 1.16 & 26.7 & 25.3 & 0.852 \\
50.0 & 10.0 & 5.0 & 3.82 & 19.0 & 20.9 & 0.991 \\
50.0 & 10.0 & 11.0 & 0.868 & 35.0 & 37.7 & 0.924 \\
\hline
\end{tabular}

They were all fits with higher values of $\left(R^{2}\right)$ ranging from 0.852 to 0.95 at all experimental conditions. Furthermore, there were small different between values of $q_{0}$ from Thomas models and qe from experiments at same conditions. These implied that Thomas models can be used to fit the experimental data and to predict the column adsorption quantity.

As shown in Table 1, as the influent concentration increased, the value of $q_{0}$ increased but the value of $k_{\mathrm{Th}}$ decreased. The reason is that the driving force for adsorption is the concentration difference between the dye on the adsorbent and the dye in the solution. Thus the high driving force due to the higher NR concentration resulted in better column performance. With flow rate increasing, the value of $q_{0}$ slightly decreased but the value of $k_{\mathrm{Th}}$ increased. As the bed depth increased, the value of $q_{0}$ increased significantly while the value of $k_{\text {Th }}$ decreased significantly. So higher flow rate and lower influent concentration have disadvantage of adsorption quantity of NR on WS column. But for removal efficiency, there were higher breakthrough time with lower NR concentration, lower flow rate and higher bed depth.

\section{Conclusions}

On the base of the results, the following conclusion can be drawn:

a. Influent NR concentration, flow rate of solution and bed depth significantly affect the breakthrough curve.

b. WS as low-cost adsorbent can efficiently remove NR from solution.

c. Thomas model was available to fit the experimental data and predict the column adsorption quantity. 


\section{Acknowledgements}

This work was supported by the National Natural Science Foundation of China for undergraduate cultivation in basic science (J1210060).

\section{References}

[1] A. Bhatnagar and M. Sillanpaa: Chem. Eng. J. Vol. 157 (2010), p. 277.

[2] G. Crini: Bioresour. Technol. Vol. 97 (2006), p. 1061.

[3] X. Xu, B.Y. Gao, B. Jin and Qi.Y. Yue: J. Mol. Liq. Vol. 215 (2016), p. 565.

[4] V.K. Gupta, Suhas: J. Environ. Manage. Vol. 90 (2009), p. 2313.

[5] I. Ali, M. Asim, T.A. Khan: J. Environ. Manage. Vol. 113 (2012), p. 170.

[6] M.A.M.Salleh, D.K. Mahmoud, W.A.W.A. Karim, A. Idris: Desalination Vol. 280 (2011), p. 1.

[7] Y.J. Wu, L.J. Zhang, C.L. Gao, J.Y. Ma, X.H. Ma and R.P. Han: J. Chem. Eng. Data Vol.54 (2009), p. 322.

[8] R.P. Han, L.J. Zhang, C. Song, M.M. Zhang, H.M. Zhu and L.J. Zhang: Carbohyd. Polym. Vol. 79 (2010) p. 1140.

[9] Y.K. Li, B.L. Zhao, L.J. Zhang, R.P. Han: Desalin. Water Treat. Vol. 51 (2013), p. 5735.

[10] Y.Y. Su, B.L. Zhao, W. Xiao, R.P. Han: Environ. Sci. Pollut. R. 20 (2013), p. 5558.

[11] R.D. Zhang, J.H. Zhang, X.N. Zhang, C.C. Dou, R.P. Han: J. Taiwan Inst. Chem. E. Vol. 45 (2014), p. 2578.

[12] X.F. Ren, X.N. Zhang, L.J. Zhang, R.P. Han, Desalin Water Treat. Vol. 51 (2013), p. 4514.

[13] Z. Akzu and F. Gonen: Process Biochem. Vol. 39 (2004) p.599.

[14] Z. Xu, J.G. Cai, B.C. Pan: Zhejiang Univ. Sci. A (Appl. Phys. \& Eng.) Vol. 14 (2013), p. 155.

[15] R.P. Han, L.N. Zou, X. Zhao, Y.F. Xu, F. Xu, Y.L. Li, Y. Wang: Chem. Eng. J. Vol. 149 (2009), p. 123. 